for a careful investigation of developmental psychopathology following abuse, which investigation will surely reveal the complexity of vulnerability and risk factors, age and personality influences, which have characterised research into the consequences of other severe stresses in childhood. As we streamed out into
London, I imagine that most of us felt somewhat reassured and empowered by the day.

Tutor in Child \& Adolescent Psychiatry

J. GREEN

Royal Manchester Children's Hospital

Swinton, Manchester

\title{
Psychiatry and Court procedures
}

This report was produced by the Irish Division in response to a request from the Medical Council. It has been approved by the Executive Committee and the general body of the Irish Division. It has also been submitted and approved by the Executive and Finance Committee of the Royal College of Psychiatrists.

There are two main areas of psychiatric involvement in the legal process:

(a) Psychiatrists may be asked to examine individuals and to formulate professional opinion for legal purposes.

(b) Psychiatrists may be asked to attend court as expert witnesses. Technically the evidence in court can be divided into the witnessing of facts and the delivery of expert opinion but such separation does not arise in practice. (The non-expert witness is simply a witness of fact).

Psychiatry can be of value in both criminal and civil cases.

Civil cases. Civil cases include personal injury and mal-practice actions. Psychiatric testimony is often requested in family law cases involving child custody and access following marital breakdown. Finally psychiatrists may be asked for advice on testamentary capacity.

Criminal issues. Advice may be sought on "fitness to plead". To satisfy the fitness criteria the accused must be able to understand the nature of the charges against him and to be able to co-operate in his own defence. This obviously includes a capacity to instruct his legal advisers and to assist, if necessary, in the selection of jurors and to understand the evidence produced in court.
Criminal responsibility. The psychiatrist may be asked to assist the court in determining whether the defendant was legally insane at the time of the criminal act. In Irish courts, McNaughton rules still operate although modified by recent decisions. For a defendant to be judged legally insane it must be shown that he failed to understand the nature and quality of the criminal act and the wrongfulness of the act. McNaughton is often quite unsatisfactory, depending almost entirely on cognitive functioning. Irish courts will now ask whether the accused was, by reason of mental illness, unable to refrain from committing the act complained of. That brings us close to the concept of diminished responsibility - a plea which is not acknowledged formally in this country. In practical terms, psychosis and more severe forms of mental handicap fit easily with the legal concept of insanity but psychiatric relevance can extend beyond such illness confines.

Disposition. A psychiatrist may be able to help the court towards appropriate disposition, particularly where there is identifiable illness or behaviours that may respond to treatment and supervision.

The psychiatrist as a witness. The court has right of access to all available evidence which will help it to reach the correct decision in each individual case. The psychiatrist is expected to attend and to tell the truth under oath. Like any other witness the psychiatrist can be subpoenaed.

Clinical files. Concern is frequently expressed about the subpoena of clinical files with all their confidential, sensitive material. As already stated, the court has a right to view and hear all the evidence and that can include the clinical records, but it also has an obligation to act in the best public interest and that 
would not include the open revelation of intimate personal or family detail that is not strictly relevant to the case being tried. To protect personal intimacies from court interest it is probably safer as a general rule to leave the clinical file in the office, to keep it out of the witness box. The notes brought to court should simply be reminders of detail such as examination dates, dates of admission and discharge etc., to help the witness in his professional testimony. The court may ask to see the notes but no embarrassment will ensue. If compromised into revealing uncomfortable detail under cross examination one can appeal to the judge for guidance, explaining the professional predicament.

Presentation. Psychiatric evidence should obviously be clear and understandable to the legal profession and the lay jury. Technical terms are best avoided. One's obligation is purely to explain to the judge and jury how mental illness may have affected behaviour. The question of whether illness reduces legal responsibility is a matter for the court.

The nature of expert evidence. Abuse of psychiatric testimony, particularly in the United States, has not improved the public image of psychiatry. It is acknowledged that psychiatry, because of the subjectivity of much of the data on which psychiatric decisions must be based, is open to bias and influence in the context of the adversarial legal system. It is quite difficult to avoid over-identification with the side that employs you and objectivity can be sacrificed when one gets caught up in defence or prosecutory enthusiasm. A psychiatrist should not assume the mantle of authority and expertise unless he can back it up with extensive experience and familiarity with the relevant literature and research. There is little point in an adult psychiatrist, for example, presenting as expert in child psychiatric matters. A further example would be the hazards of giving a very firm opinion in the difficult matter of predicting dangerousness.

Providing court reports-obligation $v$. avoidance. Some psychiatrists seek to avoid court reportage altogether while others are attracted to it. Publicity often attends psychiatric evidence and the phenomenon of centre staging is a genuine trap for the unwary. Once admitted as expert the psychiatrist will find that his opinion is treated with enormous respect and this can affect the quality of psychiatric evidence. The psychiatrist is open to the temptation to extend opinion beyond levels of professional competence. Psychiatrists giving evidence should therefore guard against the danger of turning uncertainty into dogma and they may have to leave the court with unresolved complex issues to which there is no definite response.
Compiling a report for court. Preparing a report for any third party - court, insurance company, solicitor-is different to a report arising from the traditional type of doctor/patient consultation. All medico-legal reports are potentially harmful or embarrassing to the subject and they are open to cross examination in court.

In carrying out examination of a person for the purpose of a court report, psychiatrists should do their best to ensure that the subject of the report appreciates the factors mentioned above. However, despite careful explanations, defendants or clients will frequently reveal material about themselves and their background beyond their best interests. Such material may incriminate them later and exclude their choice of changing from a guilty to a non-guilty plea in criminal cases. Clients bring to the examining psychiatrist the attitudes, often trusting attitudes, from former doctor/patient interaction. Despite cautionary warnings they run the risk of harming their own case. For these reasons many forensic psychiatrists are now unhappy about focusing on events surrounding offence behaviour and on previous offence behaviour. Equally, circumspection is required in the eliciting of details of intimate family history which might subsequently prove damaging. It needs to be remembered that the family is not on trial and highlighting family disruption and pathology in a public setting such as the court room seems basically unfair.

For these reasons it is probably advisable to exclude detailed and specific family aetiologies of illness from medico legal reports unless these seem absolutely necessary.

Reports on file. Once a report is committed to writing it will inevitably be photocopied and widely distributed. One way of trying to protect against this is to head reports "private and confidential, not to be read in open court, not to be photocopied without the permission of the addressor". This may achieve some reduction in the number of copies but it will not prevent the practice. Not every reporting psychiatrist is aware that prison files continue to contain reports carried out ten or 15 years earlier in child guidance clinics on individuals who by now have become adult defendants.

Just how long psychiatric reports should stay on file is not at the moment subject to any strict regulation.

Access to reports. Since the report passes through several hands, its confidentiality obviously becomes meaningless. Quite frequently, and writers of reports should know this, the report will be seen by the defendant in criminal cases or the plaintiff in civil cases. When reporting on potentially dangerous individuals that is something that has to be kept in mind. 
Over-identification $v$. under-identification. There is an understandable tendency for all doctors, including psychiatrists, to anticipate what the court may decide in a particular case. A class bias or a personal bias can, and sometimes does, enter professional medical reports. For example, medical evidence may be influenced, perhaps less than consciously, by the reporter's personal views on the appropriateness or otherwise of harsh sentencing for defendants from social class 1 . Sexual offenders frequently elicit angry responses that can translate into biased reporting also. Over-identification can also be problematic either with the subject or with what some refer to as "the control apparatus" (courts, prisons, the Gardai, even psychiatry itself). The medical function does not of course include suggesting or influencing sentencing policy, and recommendations such as "there is little to be gained from sentencing this man" etc. should be avoided.

Changing sides. If examination of a subject uncovers material detrimental to the case and, ipso facto, beneficial to the other side, crossing over or changing sides is not ethically permissible. A problem can arise where the treating psychiatrist is asked to join the state prosecutor against his patient. He should refuse and only give evidence if subpoenaed, making the court aware of his ethical dilemma.

The reports of other experts. Occasionally one is asked by Counsel or by a solicitor to comment on descriptions, terms or conclusions in reports submitted by colleagues and other professions. The nature of psychiatric testimony obviously may involve the reports of psychologists and social workers but there is enough dilemma attached to explaining and justifying one's own professional opinion without making intrusions into the reports of colleagues, and invitations to do this should be resisted.

The question of hearsay evidence. Much of psychiatric evidence can be classified as hearsay. However, such evidence is seldom challenged on these grounds.
Psychiatric diagnosis is not based solely on what the patient says - rather it is based on the totality of interviewing and observing and piecing together all the information.

In ordinary professional practice the collection of background data is frequently delegated to professional colleagues. Psychiatrists frequently use reports from social worker and psychologist colleagues to complete a diagnostic formulation. Where serious charges are brought it may generally be recommended that the doctor should base his report as much as possible on information elicited personally. Being thorough in this matter may mean spending a lot of time on essentials including home visiting and family interviewing rather than depending on reports from other professionals. Where parts of a psychiatric report are based on information collected by others this should be clearly indicated in the report itself.

Reporting without direct examination. Occasionally psychiatrists may be requested to give an opinion without having the opportunity to examine the individual in question. For example, testamentary capacity may be challenged after death and firm opinions expressed about ante mortem psychopathology based on case notes etc. Where the subject is living and refusing examination a special dilemma may arise. This is a contentious area and the main obligation of the reporting psychiatrist is to clarify the circumstances of his report and the consequent limitations of his conclusions quite clearly. No hard and fast rules can be laid down in this area, especially in unusual instances where case records have been impounded by the court. There is of course a difference between clearly recorded facts indicating major psychiatric illness and mental handicap as opposed to documentation of "soft" and relatively unreliable diagnostic concepts such as personality disorder where inter rater reliability on diagnosis is notoriously low. Opinions can still be given in these cases but the limitations of professional conclusions should be highlighted for the court.

\section{Induction course for new tutors}

A one-day induction course intended for newly-recognised tutors, and those in the process of applying for College recognition, will be held at the College on 24 April 1989. Further details can be obtained from $\mathrm{Dr}$ Claire Sillince, c/o The Education Department at the College. 